\title{
STRATIGRAPHIC PALEOBIOLOGY OF AN EVOLUTIONARY RADIATION: TAPHONOMY AND FACIES DISTRIBUTION OF CETACEANS IN THE LAST 23 MILLION YEARS
}

\author{
Stefano Dominici ${ }^{1}$, Simone $\mathrm{Cau}^{2} \&$ Alessandro Freschi ${ }^{2}$ \\ ${ }^{1}$ Museo di Storia Naturale, Università degli Studi di Firenze, Firenze, Italy; stefano.dominici@unifi.it \\ ${ }^{2}$ Dipartimento di Scienze Chimiche, della Vita e della Sostenibilità Ambientale, Università degli Studi di Parma, Parma, Italy; cau.simo- \\ ne2@gmail.com, freschiales@gmail.com
}

\begin{tabular}{|c|c|}
\hline $\begin{array}{l}\text { KEYWORDS: } \\
\text { Neogene; } \\
\text { Pliocene; } \\
\text { Cetaceans; } \\
\text { Taphonomy. }\end{array}$ & $\begin{array}{l}\text { BUllet-Points ABSTRACT } \\
\text { - The majority of cetacean fossils are in Zanclean and Piacenzian deposits. } \\
\text { - Cetacean fossils are preferentially found in offshore paleosettings. } \\
\text { - Pleistocene findings drop to a minimum, notwithstanding offshore strata are } \\
\text { well represented in the record. } \\
\text { - A taphonomic imprinting on the cetacean fossil record is hypothesised, con- } \\
\text { nected with a radiation of whale-bone consumers of modern type. }\end{array}$ \\
\hline
\end{tabular}

\section{INTRODUCTION}

The study of the stratigraphy and taphonomy of Neogene cetaceans is a fundamental step to properly frame the evolutionary radiation of this megafauna, at the top of the pelagic marine ecosystem. Major evolutionary steps have been summarised in recent studies, taking the cetacean fossil record at face value and, while the emergence of modern adaptations during the Neogene is not questioned (Berta et al., 2015; Marx et al., 2016), still the comparison of diversity between time intervals may be hampered by the quality of the record, some evidence suggesting that some facies are associated with a better fossil record than others (Dominici et al., 2018). Nineteen cetacean families are known in the Miocene, an epoch characterized by the radiation of odontoceti and crown baleen whales. During the Pliocene many large and small odontoceti went extinct, while delphinids radiated, together with balaenoidean and thalassotherian mysticeti, two groups comprising today the largest tetrapods in the history of life (Steeman et al., 2009; Marx et al., 2015). The present study aims at collecting evidence as to the facies distribution of the fossils upon which these diversities have been calculated.

Changes in marine megafauna (MM) biodiversity appear to be strongly correlated with climate change. An important extinction event has been identified in the late Pliocene (between 3.8-2.6 Ma) and related to enhanced climatic variability, higher-amplitude sea-level oscillations and loss of productive coastal habitats (Pimiento et al., 2017). Cetaceans are the largest animals among $\mathrm{MM}$ and form the largest part of the MM fossil record (91 genus out of 215: Pimiento et al., 2017). The foothills of the Northern Apennines offer a particularly rich cetacean fossil record and an area where available studies allow to explore this key time of cetacean evolution at a stratigraphic resolution finer than the stage. An increase in cetaceans diversity is recorded around $3.2-3.0 \mathrm{Ma}$, in coincidence of the mid-Piacenzian climatic optimum, and a drastic decline at the Piacenzian-Gelasian boundary (Dominici et al., 2018; Freschi et al., in press). Starting from this evidence, the present study aims at exploring if measured taxonomic diversity can be taken at face value, or if it is an artifact of the fossil record, by adding data from the literature of Neogene cetaceans of other geographic areas.

\section{Materials AND Methods}

To check for a facies influence in the taphonomy of Neogene cetaceans, we carried out a survey of 255 papers dealing with Neogene cetaceans reaching a global picture to the exclusion of Southern America (a complete list is available from the authors upon request), including the Northern Apennine record. The exclusion of the Southern American record is due to its association with hypoxic or anoxic settings, favouring preservation, but never encountered in other areas and not evenly distributed in the Neogene. We matched individual specimens with sedimentary facies and time interval, and listed the number of bones per skeleton, ranging from the Aquitanian to the Calabrian (102 Northern Apennine specimens; 255 total specimens from North America, Europe and Japan, with chronostratigraphic data; 117 total specimens with data on sedimentary facies). Given the extension of the study to little known stratigraphic settings, stratigraphic resolution was that of the stage for the Pliocene, or

Corresponding author email: freschiales@gmail.com

How to cite: Dominici et al. (2018). Stratigraphic paleobiology of an evolutionary radiation: taphonomy and facies distribution of cetaceans in the last 23 million years. Fossilia, Volume 2018: 15-17. https://doi.org/10.32774/FosRepPal.20.1810.051517

FOSSILIA - Reports in Palaeontology 
coarser for the Miocene and the Pleistocene.

\section{Results}

Our analysis highlights a strongly skewed distribution of findings, both in space (seven facies bins) and time (six time bins). The vast majority of fossils are found in offshore mudstones (44\%) and offshore sandstones $(28 \%)$, with condensed sections being particularly important in the Miocene. The lowest abundances are recorded in shoreface sandstones, whereas completeness, measured as the average number of bones per skeleton, is higher in offshore mudstone and delta sandstone facies, meaning that the two facies bear the most complete skeletons. When plotting the number of findings $(\mathrm{N}=255)$ per time interval, standardizing for the duration of each time bin (N/Ma), a slight increase is recorded during the Miocene, a stepwise increase at the passage upper Miocene-Zanclean, follow by a Piacenzian peak and a dramatic drop at the Pleistocene, where the global number of skeletons falls to a minimum (Fig. 1A). To understand the origin of this bias, we analyzed $(\mathrm{N}=131)$ the distribution of facies in time and found a reasonably even distribution of facies per time interval (Fig.1B). This pattern suggests that the Piacenzian peak in biodiversity is in part an artifact of the record.

\section{Discussions}

In the Pliocene of Tuscany articulated specimens and rather complete skeletons are associated with offshore mudstones deposited at an estimated depth of 30-300 $\mathrm{m}$, suggesting that very shallow and very deep (bathyal) depths are generally unfavourable to the preservation of bones (Dominici et al., 2018). An analogous environmental control on the degree of articulation and completeness of fossil cetacean skeletons is also observed in the Pliocene of Emilia and Piedmont, positively correlated with offshore mudstones and biocalcarenite transgressive shell-beds, whereas no skeletons are associated with shoreface sandstones, and rare occurrences in epibathyal mudstones (Freschi \& Cau, 2016).

Our study suggests that going from shallowest to deepest, the delta front processes allow skeletons to be well-preserved due to high sedimentation rates that quickly cover the carcasses that sequesters them before they can be destroyed. In shoreface depths, carcasses refloat after sinking, then become dismembered and very frequently dispersed. On the contrary offshore depths, carcasses sink and remain on the seafloor because of a higher pressure that arrests abdominal gas production, minimizes decomposition, and in the absence of a specialized fauna, are not disassembled before burial. Carcasses remain on the seafloor also when they sink below the shelf break. However, here they become the food for a complex and specialized whale-fall fauna, characterized by bone-eating worms and other taxa that finally destroy all bone material (Smith et al., 2015). The dominance of offshore sediments in the Pliocene record explored here sugge-
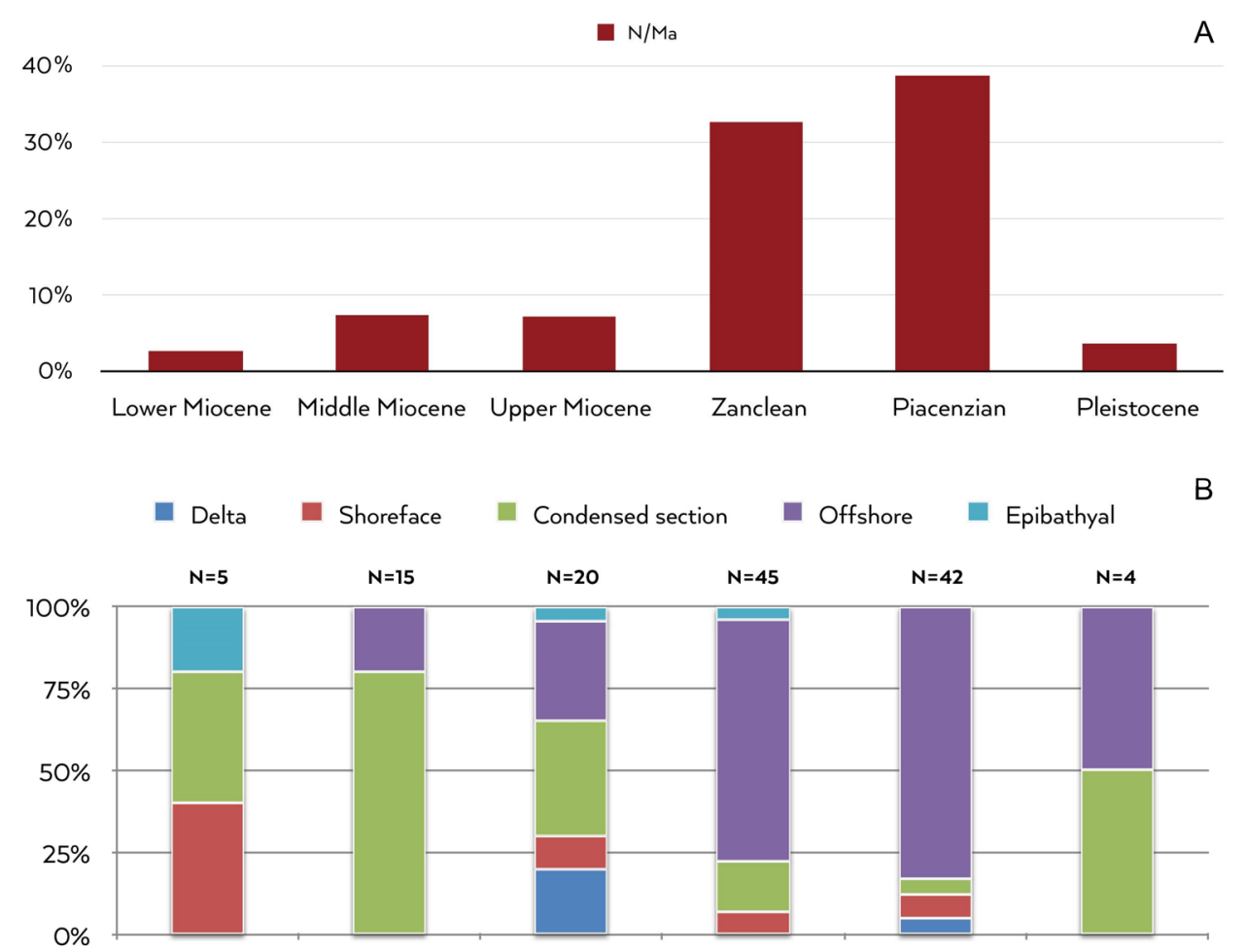

Fig. 1. A, Distribution (\%) of the findings $(\mathrm{N}=255)$ per time interval, standardized for the duration of each time interval ( $\mathrm{N} /$ $\mathrm{Ma}) ; \mathbf{B}$, Distribution of fossils $(\mathrm{N}=131)$ and facies for time bin. 
sts that the peak of Neogene biodiversity trend is in part an artefact of a taphonomic influence. Finally, we suggest that the sudden drop in the number of Pleistocene findings, notwithstanding the proper facies is widespread in Italy, is also strongly affected by taphonomic factors. The fact that this passage coincides with the onset of the evolutionary radiation of very large baleen whales and with their almost doubling in maximum size (Marx et al., 2016) — which should instead contribute a far better record - must have also triggered the radiation of bone eaters, with the counterintuitive effect of making extremely unlikely for cetacean bones to become preserved. Modern worldwide data confirm that even the largest whale skeletons are rapidly destroyed at deep-water settings (see references in Dominici et al., 2018).

\section{CONCLUSIONS}

In this work a large dataset of stratigraphic and taphonomic global literature data of Neogene cetacean is analysed (Southern America excluded). Abundance and diversity are low during the Miocene, they peak during the Pliocene, mainly in association with offshore sediments, and drasticly drops in the Pleistocene, irrespective of facies and notwithstanding the large size attained during this epoch by cetaceans should be correlated with a better record. The worsening of the record during the Pleistocene may be related to a radiation of bone-eaters, completely destroying carcasses in a matter of years in modern bottoms. In general, our study suggests a taphonomic imprinting in the distribution of abundance and diversity of Neogene cetaceans.

\section{ACKNOWLEDGEMENTS}

We thank Raymond L. Bernor and an anonymous reviewer for their useful suggestions.

\section{REFERENCES}

Berta A., Sumich J. \& Kovacs K. (2015). Marine Mammals. 3rd Edition, Elsevier, 738 pp.

Dominici S., Danise S. \& Benvenuti M. (2018). Pliocene stratigraphic paleobiology in Tuscany and the fossil record of marine megafauna. Earth-Science Reviews, 176: $277-310$

Freschi A. \& Cau S. (2016). Distribuzione geografica dei cetacei fossili del Bacino Plio-pleistocenico di Castell'Arquato (Piacenza). Parva Naturalia, 11: 47-59.

Freschi A., Cau S., Monegatti P. \& Roveri M. (in press). Chronostratigraphic distribution of cetaceans in the Pliocene of Northern Apennines (Italy): palaeoecological implications.

Marx G. M., Lambert O. \& Uhen M. D. (2016). Cetacean Palaeobiology. Topics in Paleobiology, Wiley-Blackwell, $336 \mathrm{pp}$.

Pimiento C., Griffin J. N., Clements C. F., Silvestro D., Varela S., Uhen M. D. \& Jaramillo C. (2017). The Pliocene marine megafauna extinction and its impact on functional diversity. Nature ecology \& evolution, 1 (8): 1100.

Smith C. R., Glover A. G., Treude T., Higgs N. D., Amon D. J. (2015). Whale-fall ecosystems: recent insights into ecology, paleoecology, and evolution. Annual Review of Marine Science, 7: 571-596.

Steeman M. E., Hebsgaad M. B., Fordyce R. E., Ho S. Y. W., Rabosky D. L., Nielsen R., Rahbek C., Glenner H. Sorensen M. V., \& Willerslev E. (2009). Radiation of extant cetaceans driven by restructuring of the oceans. Systematic Biology, 58: 573-585.

Manuscript received 27 July 2018

Received after revision 29 September 2018

Accepted 1 October 2018 